\title{
The assessment of the relationship between narcissism, perceived parental rearing styles, and defense mechanisms
}

\author{
Ahmet Hamdi Imamoglu' ${ }^{\circledR}$, Aysegul Durak Batigun ${ }^{2 \oplus}$ \\ 'University of Health Sciences, Institute of Health Sciences, Department of Psychology, Istanbul - Turkey \\ ${ }^{2}$ Ankara University, Faculty of Languages History and Geography, Department of Psychology, Ankara - Turkey
}

\begin{abstract}
Objective: The aim of the study was to determine the relationships between grandiose and vulnerable narcissism, perceived parental rearing styles and defense mechanisms. Besides, it was investigated how grandiose narcissism and vulnerable narcissism scores differ in terms of demographic variables such as gender and age.

Method: The study was carried out with 508 participants between the ages of 18-65 determined by the appropriate sampling method. 271 of the participants were female (53.3\%), 237 of them were male (46.7\%). The data were collected through a battery including Demographic Information Form, Pathological Narcissism Inventory, Narcissistic Personality Inventory-16, Abbreviated Perceived Parental Attitudes Scale-Child Form, Defense Style Questionnaire-40, and Splitting Scale.

Results: Statistical analyses revealed that while there was no significant difference in vulnerable narcissism scores between male and female participants, male participants had significantly higher scores in grandiose narcissism. The findings indicate a decrease in both vulnerable and grandiose narcissism as the age of the participants increase. The regression analyses showed that grandiose narcissism scores were predicted by the paternal rejection and the maternal emotional warmth as perceived parental attitudes, and by the immature defense style, splitting defense mechanism, and neurotic defense style as defense styles; vulnerable narcissism scores were predicted by the paternal rejection, maternal overprotection, splitting defense, and all forms of defense.

Conclusion: Findings that narcissistic personality may be correlated with some inadequate parental attitudes and more frequent use of defense mechanisms were discussed within the framework of this topic. In addition, the results were elaborated regarding the theoretical framework of narcissism, and how it can be used in clinical practice with narcissistic individuals.
\end{abstract}

Keywords: Defense mechanisms, grandiose narcissism, perceived parental rearing styles, splitting defense mechanism, vulnerable narcissism

\section{INTRODUCTION}

The concept of narcissism expresses the exaggerated love that one directs at oneself and his indifference towards others. Narcissism, which is referred to in the literature with its unique forms of relating and defending, has been frequently examined by theorists particularly from the psychoanalytic tradition since the

How to cite this article: Imamoglu AH, Durak Batigun A. The assessment of the relationship between narcissism, perceived parental rearing styles, and defense mechanisms. Dusunen Adam The Journal of Psychiatry and Neurological Sciences 2020;33:388-401.

Correspondence: Aysegul Durak Batigun, Ankara University, Faculty of Languages History and Geography, Department of Psychology, Ankara - Turkey

E-mail: batigun@ankara.edu.tr

Received: June 09, 2020; Revised: July 12, 2020; Accepted: September 26, 2020 
beginning of the last century and has become one of the popular terms of our time (1). While some individuals with narcissistic personalities exhibit typical narcissistic traits such as arrogance, dominance and grandiosity; it is stated that some of them have an implicit narcissistic nature concealed by characteristics such as shyness and humility (2). Due to its complex structure, narcissism has been classified in different ways by many theorists and evaluated as a multidimensional structure (3). Cain et al. (4) determined that these dimensions generally reflect two themes: grandiose and vulnerable. This distinction has also been supported by various studies $(5,6)$ and has been widely accepted in the narcissism literature (7). Grandiose narcissism is basically characterized by exploiting, low empathy, jealousy, aggression and pretentiousness (3). It has been reported that individuals with grandiose narcissistic characteristics have an intense desire to maintain their positive self-perception and feel the need to gain the admiration of others (8). According to Gabbard (9), individuals with such a personality structure have a low awareness of what kind of effect they have on others and are insensitive to the needs of others. These individuals also tend to have rude and arrogant attitudes in their interpersonal relationships (10).

Vulnerable narcissism, on the other hand, includes personality patterns that are often regarded as the opposites of grandiose narcissistic traits. However, it is thought that these two sub-dimensions of narcissism do not completely exclude each other and that many narcissistic individuals can exhibit the characteristics of both types together (11). Individuals with vulnerable narcissistic traits are hyper-sensitive to the reactions of others, avoiding being the center of attention, and are shy (9). However, it has been stated that they have grandiose fantasies that are not clearly displayed under their humble and shy images (12). Also, over-idealizing others (13); embarrassment for grandiose desires (9); excessive critical attitudes towards the self (14), dysphoric affection and pessimism have also been associated with vulnerable narcissism (12).

Studies show that the attitudes adopted by parents in their interactions with their children play an important role in the development of the child's personality and psychopathologies (15). Regarding the effects of parental attitudes on the development of narcissistic personality structure, views emphasizing excessively tolerant, extremely intrusive or cold/strict parenting styles come to the fore. (16). For example, according to Kernberg (17), one of the important factors underlying pathological narcissism is that it superficially displays functional parental behaviors; but more fundamentally it is the parent (usually mother) figure with an indifferent, cold, or implicitly aggressive attitudes. Young et al. (18) listed childhood experiences accompanying narcissistic personality development within a schematic model as loneliness, inadequate boundaries, being used or directed, and conditional approval. According to this approach, narcissistic individuals did not acquire any true love, empathy and closeness in their childhood. In a study conducted by Cramer (19), vulnerable narcissism was positive with the authoritarian parenting style of the mother; it was found to be negatively correlated with maternal attitudes perceived as sensitive and permissive. However, grandiose narcissism is positive with the father's authoritarian parenting style and it was concluded that there was a negative relationship with the father's perceived sensitive and tolerant attitudes.

Defense mechanisms are also one of the variables whose relationship with narcissism is often discussed. These mechanisms generally serve to keep affections within the limits of which the individual can cope with, to restore the psychological balance disturbed by the increase in impulses, and to deal with life events that create sudden and drastic changes in self-design, and conflicts with other important people (20). However, it has been indicated that strict, inappropriate and excessive use of defense mechanisms are associated with various psychopathologies and interpersonal problems $(21,22)$. Studies examining the relationship between narcissism and defense mechanisms highlighted the relationship between narcissism and immature defenses. It has been suggested that these individuals mostly use defense mechanisms of splitting, avoidance, denial, outpacing, commitment, projection, and projective identification (23). One of them, the splitting defense mechanism has a distinct feature in its relationship to narcissism. It is stated that narcissistic individuals often use the defense of splitting (17,23-25). The splitting defense mechanism refers to the separation of opposing affections and positive and negative representations of the self and others, and it is seen as the basic defense mechanism of infancy when the ego still lacks the capacity to integrate good and bad (26). In this period, the baby wants to separate the good self and object designs that are formed as a result of satisfying experiences from the bad self and object designs determined by frustration and aggressive impulses. Thus, the splitting functions as a defense against the anxiety created by ambivalent effects (27). It is accepted that as a result of normal functioning developmental 
processes, the splitting defense mechanism is replaced by the defense of suppression, and the effect of splitting decreases in adulthood. However, as a result of a development process in which self and object representations cannot be integrated, contradictory representations continue to be actively separated from each other (17). This leads to sudden transitions from emotional situations in which the outside world and the self are perceived completely well to emotional situations in which they are perceived as completely bad (26).

Researchers draw attention to the function of some defense mechanisms closely related to personality disorders such as splitting, in coping with negative affections that occur as a result of inappropriate parental attitudes in childhood $(17,25)$. Research findings on the subject are generally based on a limited number of longitudinal studies (28) and studies measuring perceived parental attitudes within an adult sample (29). For example, in a study with children and adolescents, perceived maternal acceptance was positive with mature defense; perceived maternal and paternal acceptance was negatively associated with the immature form of defense (30).

Considering all these, it is noteworthy that the studies examining the relationship between narcissism and perceived parental attitudes in our country are limited to some thesis and do not focus on the relationship of narcissism and splitting defense and forms of defenses. In most of the studies conducted abroad, it was observed that the perceived parental attitudes were not assessed separately for the mother and father, and the dimension of grandiosity was emphasized in analyzing the relationship between defense mechanisms and narcissism. Therefore, the objective of this study is to determine the relationship between grandiose and vulnerable narcissistic traits and perceived parental attitudes and defense mechanisms. In addition, determining how grandiose narcissism and vulnerable narcissism scores differ in terms of demographic variables such as gender and age is the secondary aim of the study.

\section{METHOD}

\section{Sample}

The sample of the study was reached using the convenience sampling method, who reside in Ankara and Istanbul provinces. Considering the features and conditions such as the purpose of the study, research opportunities, the number of independent variables, and sample selection technique, it was concluded that a sample of approximately 500 people would be sufficient. As a result, 508 participants between the ages of 18-65 $($ Mean $=31.17$, standard deviation $[S D]=11.37)$ constituted the sample group. 271 of the participants were female (53.3\%) and 237 were male (46.7\%). 3.4\% were primary school graduates, $9.4 \%$ were high school graduates and $29.3 \%$ were university students whereas $57.7 \%$ were university and above graduates. $62 \%$ of the sample was single and $35.6 \%$ were married. Information on the monthly income levels of the participants was also received. Accordingly, 23\% was below $1500 \mathrm{TL}, 17.1 \%$ between 1500 TL-2499 TL, 17.1\% between 2500 TL- 3499 TL, $24 \%$ between 3500 TL-5000 TL, while $17.1 \%$ of them reported that they had an income of over $5000 \mathrm{TL}$.

\section{Measures}

Demographic Information Form: It is a form prepared by the researcher to get responses from the participants regarding their basic demographic information (gender, age, education level, income level, family structure, whether the mother and father are alive, marital status, where they live most, and whether there has been a psychiatric diagnosis in the last six months).

Pathological Narcissism Inventory (PNI): It is a 6-point Likert-type self-report scale scored $(0=$ not like me, $5=$ very similar to me) developed by Pincus et al. (31). It was adapted to Turkish was conducted by Buyukgungor (32). In this study, the number of items was reduced to 40 by removing 12 items in the original scale due to item correlations and factor loadings. As a result of the analysis, a seven-factor structure was obtained: Contingent Self-Esteem, Denial of the Dependency, Grandiose Fantasy, Exploitativeness, Entitlement Rage, Self-Sacrificing, Self-enhancement. In the Turkish version of the PNI, it was observed that 6 subscales, excluding Exploitativeness, were clustered in the Narcissistic Vulnerability dimension and this dimension explained $45.27 \%$ of the variance. It was reported that the Narcissistic Grandiosity dimension, which consists only of the Exploitativeness subscale, explained $15.21 \%$ of the variance. The Cronbach alpha reliability coefficient obtained for the total score of the scale was calculated as 0.91 ; in the subscales, this value was determined to range from 0.23 to 0.63 . Since all subscales except Exploitativeness are included in the vulnerable narcissism dimension, the Turkish version of the PNI was evaluated mainly as a tool to measure the vulnerable appearance of narcissism (32). In the present study, the Narcissistic Vulnerability related dimensions of the scale were used and the Cronbach alpha reliability coefficient was determined as 0.94 . 
Narcissistic Personality Inventory-16 (NPI-16): It is a self-report scale developed by Raskin and Hall (33) according to the narcissistic personality disorder criteria in DSM-III. Ames et al. (34) formed the 16-item form of the NPI and each of these forms has two statements. One of them indicates a narcissistic trait. Participants are asked to read these pairs of items and mark the statement they think reflects them. The adaptation to Turkish study was carried out by Atay (35), and Gungor and Selcuk (36) revised and rearranged some of its statements. The Cronbach's alpha internal consistency coefficient of the scale was calculated as 0.75 and 0.74 . It is accepted that the grandeur narcissistic traits of the participants increase as the scores obtained from the scale whose total score can range from 0 and 16 increase. In the present study, the Cronbach alpha reliability coefficient for NPI-16 was calculated as 0.71 .

Defense Styles Questionnaire-40 (DSQ-40): It is a self-report scale consisting of 40 items organized by Andrews et al. (37). The items are scored in Likert type between 1 (not suitable for me at all) to 9 (very suitable for me). The adaptation study of the scale was carried out by Yilmaz et al. (38). As a result of the study, three dimensions; mature, neurotic, and immature defense were obtained and the Cronbach alpha internal consistency coefficients for these dimensions were calculated as $0.70,0.61$ and 0.83 , respectively. The increase in the scores obtained from the scale indicates the increase in the use of the defense style to which the relevant defense mechanism belongs. In this study, Cronbach's alpha reliability coefficients for mature, neurotic and immature defense style subscales were calculated as $0.63,0.59$ and 0.79 , respectively.

Perceived Parenting Attitudes in Childhood- Short EMBU-Children Form (S-EMBU-C): It is a 23-item scale developed by Arrindell et al. (39) to assess the perceived parental attitudes of adult individuals regarding their childhood. On the scale, participants evaluate the parental attitudes they perceive during childhood separately for both their mothers and fathers. This assessment is scored 1-4 Likert-type items in three dimensions: overprotection, rejection, and emotional warmth. The Turkish adaptation study of the scale was carried out by Dirik et al. (40). In this study, the Cronbach's alpha internal consistency values in the maternal subscales were $0.71,0.68$ and 0.65 for overprotection, rejection and emotional warmth, respectively while it was $0.50,0.72$ and 0.73 for paternal overprotection, rejection and emotional warmth, respectively. High scores from subscales indicate an increase in perceived parenting attitudes for that subscale.
In the present study, Cronbach's alpha reliability coefficients were calculated as $0.80,0.83$ and 0.80 , respectively for the dimensions of the S-EMBU-C of perceived emotional warmth, rejection and overprotection regarding the mother. Cronbach's alpha reliability coefficients for the dimensions of perceived paternal emotional warmth, rejection and overprotection were found to be $0.82,0.84$ and 0.80 , respectively.

Splitting Scale (SS): It is a 7-point Likert-type scale with 14 items developed by Gerson (41) to assess the splitting defense mechanism in individuals. The scores obtained from the scale range from 14 to 98 , and higher scores indicate more frequent use of splitting the defense mechanism. The Turkish adaptation study of the scale was carried out by Alkan (42), and the Cronbach alpha interior consistency coefficient was calculated as 0.70 . The test-retest and Guttman two-half test reliability coefficients were reported as 0.85 and 0.78 , respectively. Cronbach alpha reliability coefficient in this study was calculated as 0.73 .

\section{Procedure}

First, approval was obtained from the Ankara University Ethics Committee (Approval no: 17/280 73921) and the above-mentioned measurement tools were converted into a battery. Before the study, participants were asked to sign the informed consent form by providing written and oral information about the scope and the ethical framework of the study. The application was made on an individual basis and lasted about 20-25 min. Participants with end values and the missing data above acceptable levels (more than $10 \%$ of the number of items in the scale) were excluded from the data set to make the data obtained ready for the analysis. Statistical analyses were performed with the SPSS- 21 program in line with the research questions, after assigning new values with an acceptable level to replace the missing data with the mean assignment method. In order to minimize the sequence effect, other scales were included in the battery in a different order, with the informed consent form and demographic information form appeared at the beginning.

\section{RESULTS}

\section{Analyzes on the Gender Variable}

T-test analysis was conducted for independent groups to determine whether the dependent variable scores of the study, grandiose narcissism and vulnerable narcissism, differed according to gender. As a result of 
the analysis, no significant difference was observed in terms of vulnerable narcissism scores (Male: $\mathrm{Mean}=2.39, \mathrm{SD}=0.81$ ) (Female: Mean $=2.35, \mathrm{SD}=0.90),(\mathrm{t}=0.40, \mathrm{p}>0.05]$ while men's grandiose narcissism scores (Mean $=5.46$, $\mathrm{SD}=3.14)$ was found to be significantly higher $(\mathrm{t}=3.11, \mathrm{p}<0.001)$ than women $(\mathrm{Mean}=4.62$, $\mathrm{SD}=2.99$ ).

\section{Association Between Variables (Correlation Analysis)}

Pearson Product-Moment Correlation Coefficients were calculated to determine the association between all variables considered in the study. Statistically, values of 0.05 and below $(p<0.05)$ were considered significant. In this and the following statistical analyzes, two items related to splitting defense under the immature defense style subscale of the Defense Styles Questionnaire were excluded, and the splitting defense mechanism was included in the analysis as a variable measured only by the Splitting Scale.

As a result of the correlation analysis, it was observed that there were negative and significant associations between the age variable and grandiose narcissism scores and vulnerable narcissism scores. In addition, grandiose narcissism scores show a significant relationship with the perceived maternal overprotection and perceived paternal rejection. However, the correlation coefficients between grandiose narcissism scores and other perceived parental attitudes were found to be not significant. However, vulnerable narcissism showed significant associations with all perceived parental attitudes, except for the perceived maternal emotional warmth.

The grandiose narcissism variable was found to be significantly associated with immature defense style, mature defense style and splitting defense mechanism; while the vulnerable narcissism variable was found to be associated with immature defense style, neurotic defense style, and splitting defense mechanism. However, no significant correlation was found between grandiose narcissism and neurotic defense style, and between vulnerable narcissism and mature defense style. The results are shown in Table 1.

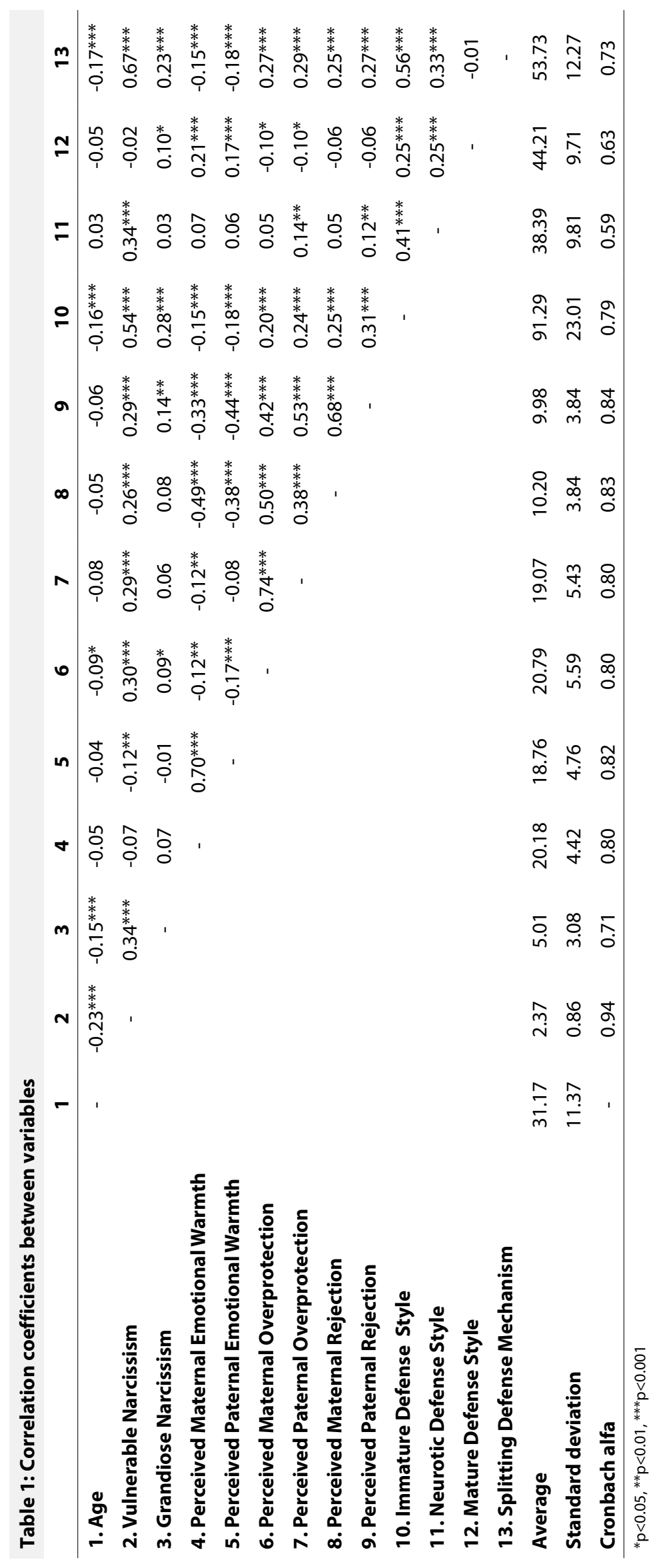




\section{Regression Analysis}

In this part of the study, two separate-stages of linear regression analysis were conducted to determine the variables that predicted the grandiose narcissism and vulnerable narcissism scores of the participants. In both regression analyzes; demographic variables (age, gender, income level) in the first stage, perceived parental attitudes (emotional warmth, rejection, overprotection) in the second stage; defense styles (immature, neurotic, mature) and splitting defense mechanism in the final stage were included in the equation.

In the first regression analysis in which grandiose narcissism was considered as the dependent variable (Table 2), the first predictor variable was age and explained $2 \%$ of the variance $(\mathrm{F}=11.05, \mathrm{p}<0.001)$. It was observed that the gender variable included in the equation in the same step increased the explained variance to $4 \%(\mathrm{~F}=11.11, \mathrm{p}<0.001)$. Among the perceived parental attitudes included in the second stage in the analysis, the perceived paternal rejection increased the explained variance to $5 \%(\mathrm{~F}=10.60$, $\mathrm{p}<0.001)$, while the perceived maternal emotional warmth to $6 \%(\mathrm{~F}=9.56, \mathrm{p}<0.001)$. In the final step, defense styles and splitting defense were included in the analysis. Among these variables, the variance explained by the immature defense style reached $11 \%(\mathrm{~F}=13.98$, $\mathrm{p}<0.001)$. While $12 \%$ of the variance $(\mathrm{F}=12.69, \mathrm{p}<0.001)$ was explained by the addition of the splitting defense mechanism, it was observed that the total variance explained by the neurotic defense style increased to $13 \%$ $(\mathrm{F}=12.04, \mathrm{p}<0.001)$. Examining the beta values, it was observed that the strongest predictor was the immature defense style $(\beta=0.22)$ followed by the perceived maternal emotional warmth $(\beta=0.16)$.

In the second regression analysis in which vulnerable narcissism was considered as the dependent variable (Table 3), only age was found to have a significant predictive effect among the demographic variables included in the first step and explained 5\% of the variance $(\mathrm{F}=27.68, \mathrm{p}<0.001)$. In the second step, the explained variance increased to $13 \%(\mathrm{~F}=37.10, \mathrm{p}<0.001)$ by the inclusion of the perceived paternal rejection from the parental attitudes in the analysis. The perceived maternal overprotection increased the explained variance to $16 \%(\mathrm{~F}=31.97, \mathrm{p}<0.001)$. In the final step of the regression analysis, the splitting defense mechanism and defense styles were involved. At this step, the splitting defense mechanism increased the explained variance to $48 \%(\mathrm{~F}=115.11, \mathrm{p}<0.001)$. It was then observed that the explained variance was $50 \%$ $(\mathrm{F}=102.78, \mathrm{p}<0.001)$ by the inclusion of the immature defense style to the model. With the contribution of the neurotic defense style, this rate reached $51 \%(\mathrm{~F}=88.68$, $\mathrm{p}<0.001)$. Finally, it was determined that the predictive effect of mature defense style was significant and the total explained variance increased to $52 \%(\mathrm{~F}=78.07$, $\mathrm{p}<0.001)$ with this variable. When the beta values were examined, it was observed that the strongest predictor was the splitting defense mechanism $(\beta=0.46)$ followed by the immature defense style $(\beta=0.16)$.

\section{DISCUSSION}

In the study, it was first examined whether the grandiose narcissism and vulnerable narcissism scores differ by gender and age. According to the findings, while the vulnerable narcissism scores of the participants showed no significant difference in terms of gender variable, the grandiose narcissism scores of the men were observed to be significantly higher than those of women. Reviewing the literature, some studies show no gender difference $(43,44)$ while in some studies, men's scores of grandiose narcissism are significantly higher than those of women, similar to the findings in this study (45-48). There are several explanations as to why grandiose narcissism is more common among men. For example, Wardetzki (49) asserted that although men and women basically have the same narcissistic disorder; the genderrelated social norms are shaping how this narcissistic nature is expressed. According to him, while the narcissistic personality of women tends to be concealed more harmoniously within the cultural structure, the narcissistic personality of the men is formed to be expressed more grandiose and omnipotent way by the cultural structure. According to Morf and Rhodewalt (50), since some characteristics such as exploitativeness, dominance and grandiosity are regarded as socially more acceptable to men, women meet their narcissistic needs more implicitly and indirectly per their gender roles. In addition to these approaches; it has been suggested that men might have acquired these characteristics more than women in the evolutionary process due to the advantages of grandiose narcissistic traits such as leadership, aggression and competitiveness in terms of continuity of species and biology (51). For all these possible reasons, more stereotypic narcissistic traits, such as grandiose narcissistic personality features, may be more common in men.

In this study, age was considered as a variable besides gender. As a result of the correlation and regression analyzes, it was observed that as the age of the individuals increased, their grandiose and vulnerable 


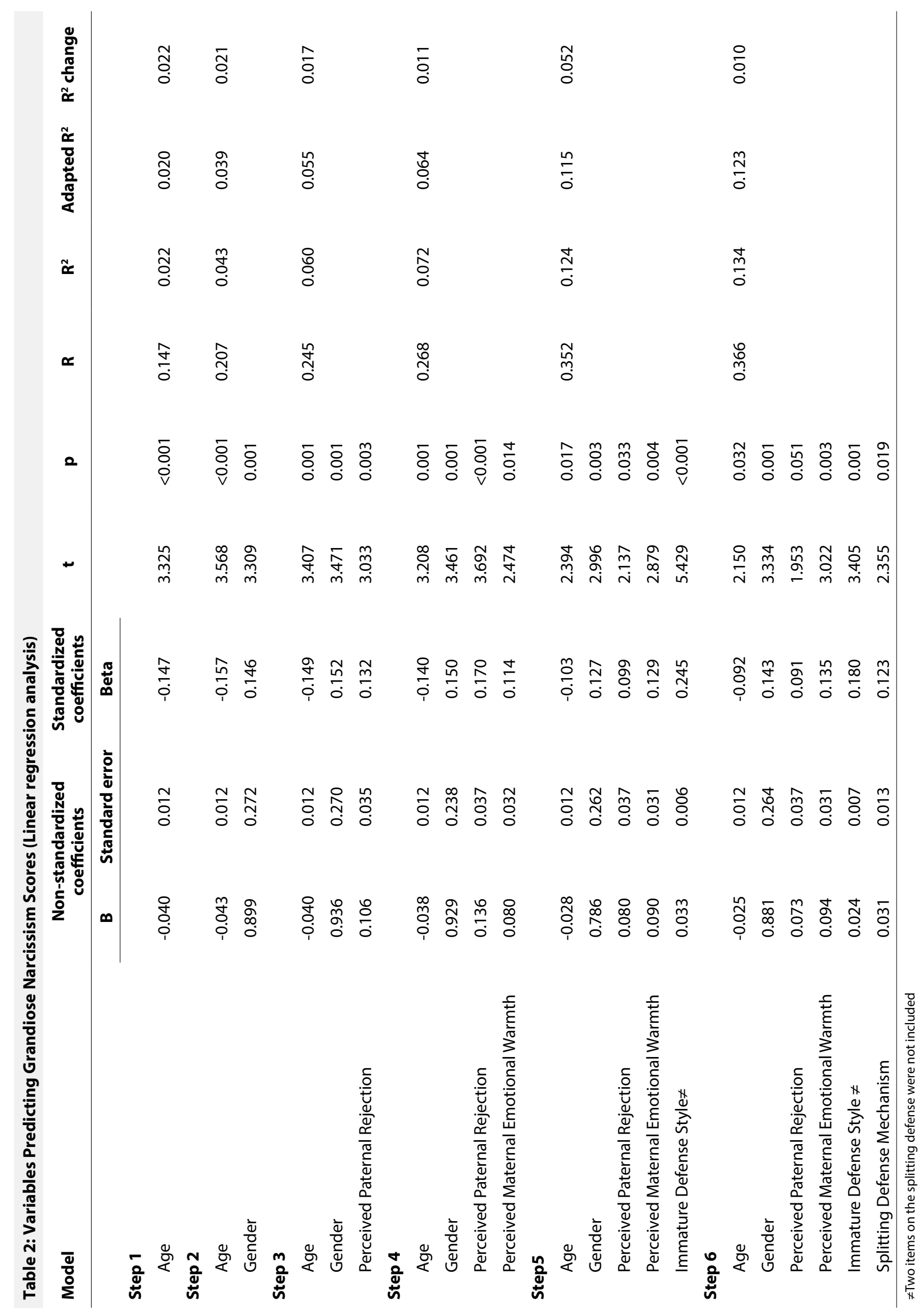




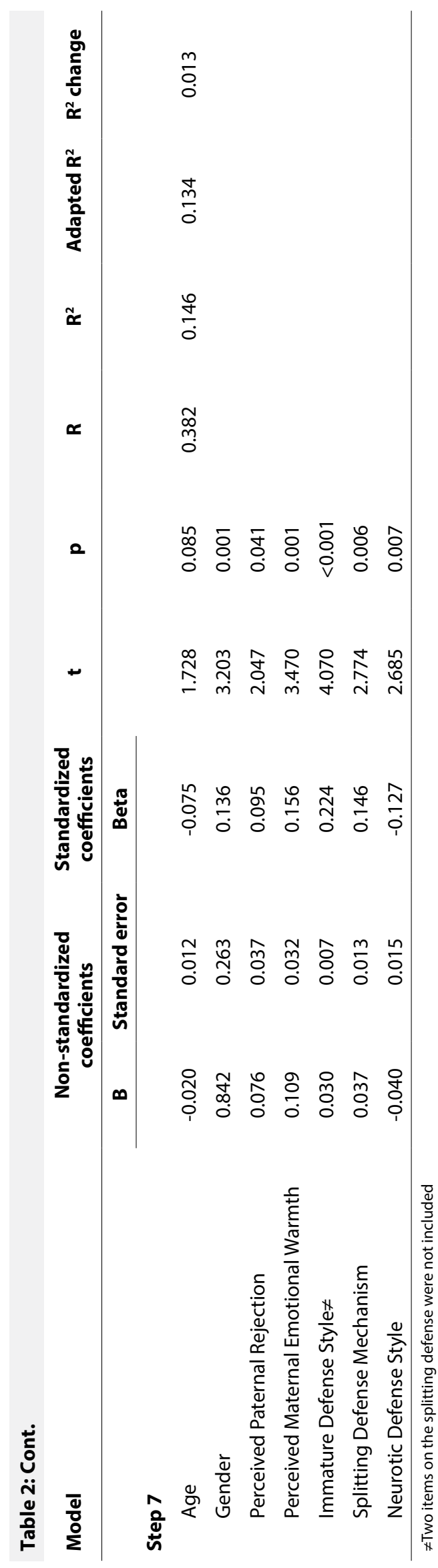

narcissistic scores decreased. The findings both in our country (43) and abroad $(47,52,53)$ suggest that narcissistic characteristics are reported less as the age gets older. Besides the period-specific developmental factors; it may be a result of differences between generations. As Ronningstam (10) stated, developmental difficulties specific to the transition period from adolescence to adulthood may cause narcissistic disorders to be seen more frequently in these individuals. Some studies were also reported that narcissism has been increasing among younger generations in western cultures $(54,55)$. In parallel with this increase, emphasis on individualism and egocentrism in many cultural elements such as advertisements, magazines and songs; there has also been an increase in the use of the 'I' pronoun $(56,57)$. Therefore, it can be argued that there is a possible increase in the symptoms of the narcissistic personality or at least the fact that these features can be expressed more clearly among the young generations with this intergenerational difference, which indicates the increasing trend of individualism in Turkish culture.

Examining the regression analysis, it is observed that the grandiose narcissism scores of the individuals increase as the perceived maternal emotional warmth and the perceived paternal rejection increases. When the literature on the subject is examined, some studies reveal that perceived parenting attitudes (such as maternal emotional warmth and paternal rejection), which can be considered at the opposite poles, may predict grandiose narcissism, similar to the current study. For example, Otway and Vignoles (58) found that perception towards both over-valuing and rejecting attitudes of the parents was associated with grandiose narcissism, and evaluated this situation as the fact that the overvalued attitudes may contain implicitly rejecting messages. Similarly, Huxley and Bizumic (59) found that parental attitudes, perceived as high-level rejecting and low-level cold, predicted grandiose narcissism. However, it should be kept in mind that most of the studies in the literature do not evaluate perceived parental attitudes towards mother and father separately. It seems that the development of grandiose narcissistic traits may be influenced by different, and sometimes even opposite attitudes of the mother and father.

When the defense mechanisms predicting grandiose narcissism are examined, it is observed that the immature and neurotic defense styles and splitting defense mechanism are significant predictors. Moreover, it is remarkable that the immature defense 


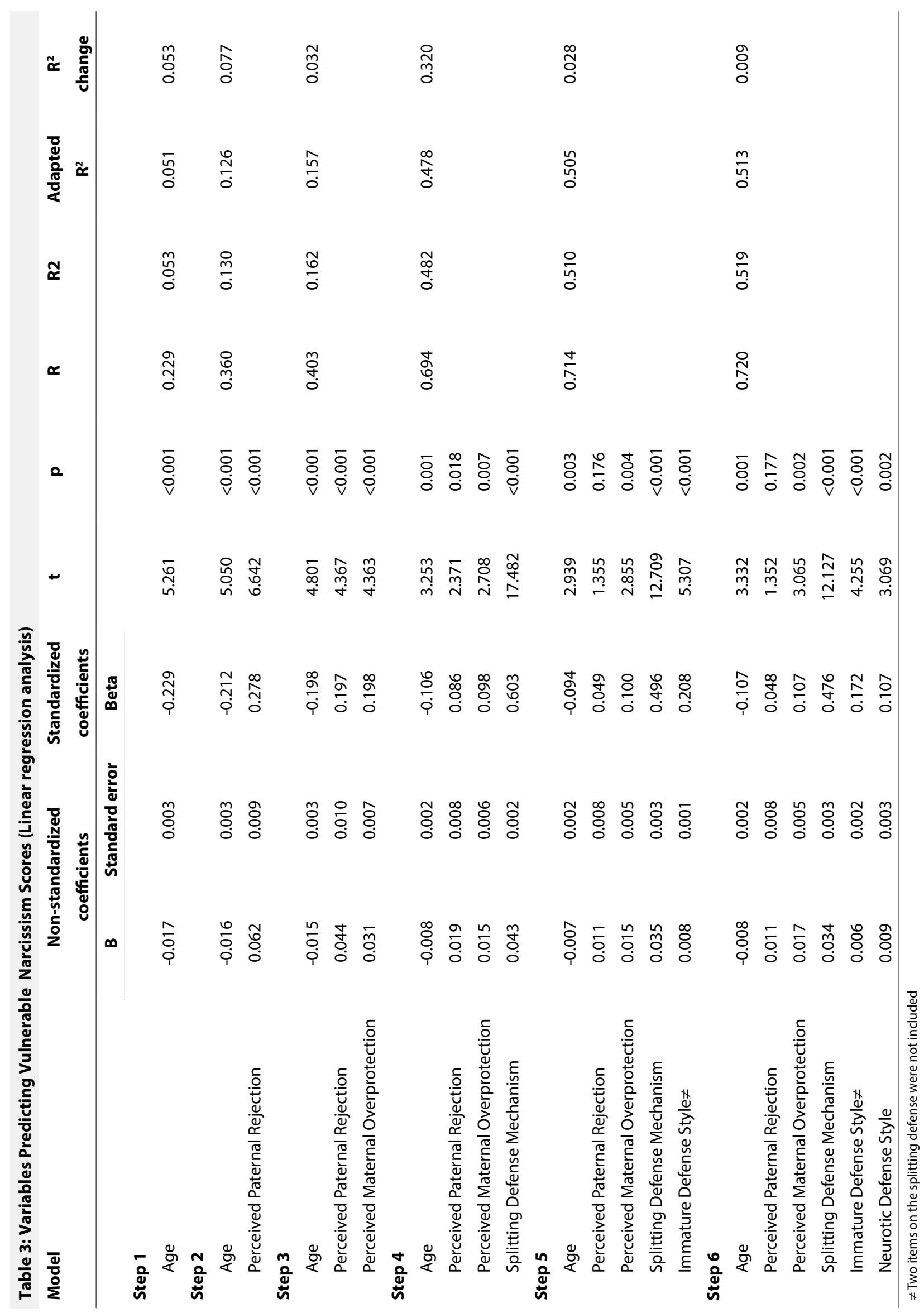




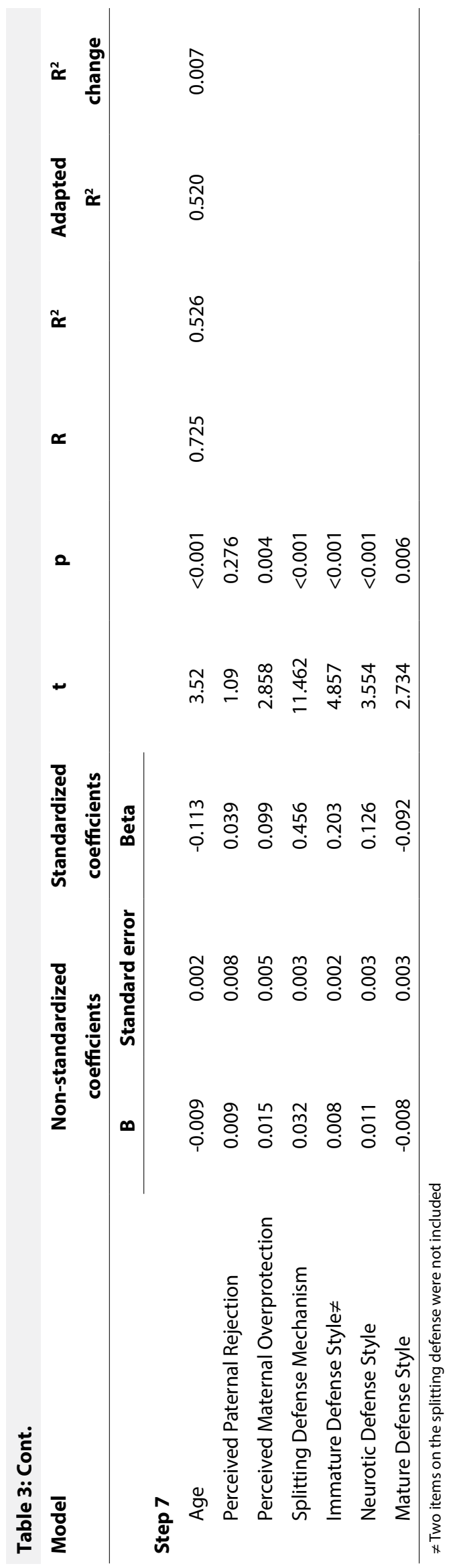

style is the strongest variable $(\beta=0.22)$ predicting grandiose narcissism. There are several studies in the literature revealing the association of narcissistic personality traits with immature defense mechanisms such as projection, denial, rationalization, projective identification, and devaluation (60-64). Similarly, findings are supporting the relationship between the splitting defense mechanism and narcissism $(65,66)$. Most of the narcissistic individuals tend to deny their weaknesses, glorify their self, and devalue stimuli that pose a threat to their self-worth (5); therefore, it is possible to assess all of these processes as defense mechanisms used to regulate self-esteem, which is highly affected by interpersonal relationships. On the other hand, as this study shows, there is no evidence in the literature that less use of neurotic defenses contributes to grandiose narcissistic traits. This finding may be due to the characteristics of the Defense Styles Questionnaire used. That is, in the neurotic defense style dimension of the test, the defenses of pseudo-altruism, undoing, idealization, and adverse reaction formation were measured. One of these defense mechanisms, idealization is generally associated with vulnerable narcissistic characteristics (23). In addition, the fact that neurotic defense mechanisms are generally aimed at resolving internal conflicts rather than problems in interpersonal relationships (67) may have led to this result.

When the regression analysis of vulnerable narcissism is examined, it is observed that the variables of perceived parental attitudes, paternal rejection and maternal overprotection, are significant predictors. When examined in the literature, it is possible to come across studies revealing vulnerable narcissism is associated with parents' perceived overprotective and rejecting attitudes or similar dimensions $(46,58,59)$. Evaluating the contribution of the maternal overprotection to vulnerable narcissistic traits from a theoretical point of view, Kohut's approach comes to the fore. Kohut (24) considered one of the important factors in the development of the narcissistic personality structure as the lack of "optimal frustration" experiences. These non-traumatic experiences, such as minor disappointments, blockings, or empathic inadequacies of the mother at an acceptable level, play an important role in harmonizing the illusion of omnipotence in the child with reality. However, since the mother's overprotective attitudes may mean that the child is deprived of the occasions to experience these frustrations, it seems possible that feelings of grandiosity are indirectly transferred into adulthood, as in 
vulnerable narcissistic individuals. However, according to the findings of this study, perceiving the father as more rejecting also contributes to the vulnerable narcissistic traits. As mentioned before, in the findings about grandiose narcissism, exposure to rejecting attitudes is a condition that some theorists often highlighted in the developmental processes of narcissistic individuals.

According to the findings, the overuse of immature and neurotic defense styles along with the splitting defense; and low use of mature defense style predicts vulnerable narcissistic traits. Although it has been reported in the literature that individuals with vulnerable narcissistic characteristics use defensive strategies in their interpersonal relationships (68), there is no study revealing specifically the relationship between vulnerable narcissism and defense mechanisms. However, as seen in the studies edited by Perry et al. (69), narcissistic personality traits are associated with the use of many immature defense mechanisms, including splitting. This relationship, as stated before, is also compatible with various perspectives that narcissistic individuals generally resort to other immature defense mechanisms, particularly the splitting defense $(23,26)$. The splitting defense mechanism ( $\beta=0.46)$, which appears to be the strongest predictor of vulnerable narcissism in this study, functions to distinguish the opposing affections of grandiosity/superiority and insufficiency/ inferiority from each other in narcissistic individuals (70). However, Masterson (23) stated that unlike grandiose narcissism, emotional investments focus on the idealized object in the split intrapsychic structures of individuals with vulnerable narcissistic characteristics; in other words, they felt valued through the relationships they established with idealized important people by suppressing their grandiose feelings. As a matter of fact, it is mentioned in this study that these individuals often resort to the idealization defense under the neurotic defense style (13). On the other hand, the findings of this study reveal that less use of mature defense mechanisms also contributes to vulnerable narcissistic characteristics. In other words, the overall findings indicate that individuals with vulnerable narcissistic characteristics are more likely to use lower-level defense mechanisms while resorting less to mature defense mechanisms. Therefore, it can be asserted that the defense mechanisms used by these individuals in reporting more psychological problems (71) and difficulty in regulating emotions (43) may play a role.
It is often emphasized by clinicians from both the psychoanalytic and the cognitive therapy traditions that clinical practices with narcissistic individuals are a challenging process (72). In this study, some findings were obtained that may play an important role in clinical practices with individuals having narcissistic personality disorder symptoms or who experience intense narcissistic vulnerability or narcissistic grandiosity. First of all, it has once again revealed that the distinction (4) between the grandiose and vulnerable narcissistic traits should not be overlooked by the therapist in clinical practice in line with the views of recent studies and theorists. As seen in this study, the vulnerable and grandiose narcissistic traits share some commonalities as well as some differences in terms of perceived parental attitudes and defense mechanisms. In this regard, it seems important to consider that vulnerable narcissistic traits (73), particularly those confused with borderline personality disorder symptoms, may have a hidden appearance behind the defense mechanisms of narcissism.

According to the findings of this study, both grandiose and vulnerable narcissism shows significant associations with some perceived parental attitudes related to mother and father, the splitting defense mechanism, and some defense styles. Therefore, in the therapeutic process, it is thought that evaluating the relationships of narcissistic individuals with their parents separately for the mother and father, interpreting these relationships within the framework of the transference reactions in therapy and the ways of establishing relationships with other people, and focusing on the affection and cognitive processes that arise in this context may play an important role in the clinical practice process. On the other hand, it can be thought that focusing on other immature defense mechanisms used by these individuals, especially the splitting defense mechanism, in order to keep affections and cognitions away from conscious awareness may contribute to clinical applications. In addition, based on the relationship between adequate and appropriate parenting styles and more mature defense mechanisms, it is thought that education, counseling and therapy services for parents may also have a protective function for narcissistic disorders in terms of their contribution to children's developmental processes.

The study has some limitations. The most important of these is that the measurement tools applied consist of self-report style scales. In self-report scales, the degree to which answers reflect reality is limited by the perception of the participants. Many factors, such as the 
desire to display oneself better or worse, cognitive distortions, the individual's mood and defensive attitudes can influence the responses of the participants. It is possible to say that the measurement tools in this study are also open to such an effect in terms of the measured variables. Another factor that may affect participants' responses is thought to be the scale battery, which contains too many items to cause boredom and fatigue.

Another point that can be considered among the limitations of the study is related to the demographic characteristics of the sample. For example, it is observed that the participants are predominantly middle-class income level and higher education level. Therefore, these factors should be taken into account in the interpretation of the research findings.

Another limitation of the study arises from the problems experienced in conceptualizing and measuring narcissism. For example, it is a matter of debate to what extent the vulnerable narcissism dimension, which indicates an implicit structure compared to grandiose narcissism, differs from the symptoms of other psychiatric diagnoses. Although the diagnosis of vulnerable narcissism is explicitly included in the psychoanalytic tradition and its subsequent approaches (74), it is possible to say that the vulnerable narcissism dimension may not have revealed a clear conceptualization in this study conducted with a nonclinical sample, and using self-report scales.

Finally, although the theoretical framework on which the research is based points to some causal factors between parental attitudes and narcissism, this research does not suggest such causality in terms of its crosssectional structure.

\begin{tabular}{|c|c|c|}
\hline \multicolumn{2}{|c|}{ Contribution Categories } & Author Initials \\
\hline \multirow{3}{*}{ Category 1} & Concept/Design & A.H.I., A.D.B. \\
\hline & Data acquisition & A.H.I. \\
\hline & Data analysis/Interpretation & A.H.I., A.D.B. \\
\hline \multirow{2}{*}{ Category 2} & Drafting manuscript & A.H.I. \\
\hline & Critical revision of manuscript & A.D.B. \\
\hline Category 3 & Final approval and accountability & A.H.I., A.D.B. \\
\hline \multirow{2}{*}{ Other } & Technical or material support & $\mathrm{N} / \mathrm{A}$ \\
\hline & Supervision & A.D.B. \\
\hline
\end{tabular}

Ethics Committee Approval: This study was approved by the Ankara University Ethics Committee (Approval no: 17/280 73921).

Informed Consent: Written informed consent obtained.

Peer-review: Externally peer-reviewed.

Conflict of Interest: There is no conflict of interest.

Financial Disclosure: There is no financial disclosure.

\section{REFERENCES}

1. Doganer I. Narcissistic personality disorder. Ege Psychiatry Periodicals 1996; 1:341-352.

2. Ronningstam E. Narcissistic personality disorder: facing DSM-V. Psychiatr Ann 2009; 39:111-121. [CrossRef]

3. Pincus AL, Lukowitsky MR. Pathological narcissism and narcissistic personality disorder. Annu Rev Clin Psychol 2010; 6:421-446. [CrossRef]

4. Cain NM, Pincus AL, Ansell EB. Narcissism at the crossroads: phenotypic description of pathological narcissism across clinical theory, social/personality psychology, and psychiatric diagnosis. Clin Psychol Rev 2008; 28:638-656. [CrossRef]

5. Dickinson KA, Pincus AL. Interpersonal analysis of grandiose and vulnerable narcissism. J Pers Disord 2003; 17:188-207.

6. Wink P. Two faces of narcissism. J Pers Soc Psychol 1991; 61:590597. [CrossRef]

7. Pincus AL, Cain NM, Wright AG. Narcissistic grandiosity and narcissistic vulnerability in psychotherapy. Personal Disord 2014; 5:439-443. [CrossRef]

8. Rohmann E, Neumann E, Herner MJ, Bierhoff HW. Grandiose and vulnerable narcissism: Self-construal, attachment, and love in romantic relationships. Eur Psychol 2012; 17:279-290.

9. Gabbard GO. Two subtypes of narcissistic personality disorder. Bull Menninger Clin 1989; 53:527-532.

10. Ronningstam E. Identifying and understand the narcissistic personality. New York: Oxford University Press Inc., 2005, 31-113.

11. Kizlltan H. Narcissism and its psychopathology 2006. http:// www.psikomitoloji.com

12. Akhtar S. The Shy Narcissist: In Sandler J, Michelshttp:// psikomitoloji.com/wordpress/2016/08/24/narsisizm-vepsikopatolojisi/ Erişim Tarihi: 11.05.2018

13. Akhtar S, Thomson JA Jr. Overview: narcissistic personality disorder. Am J Psychiatry 1982; 139:12-20. [CrossRef]

14. Cooper AM, Ronningstam E. Narcissistic personality disorder. American Psychiatric Press Review of Psychiatry 1992; 11:8097.

15. Okagaki L, Luster T. Research on parental socialization of child outcomes: Current controversies and future directions: In Luster T, Okagaki L (editors). Parenting: an ecological perspective. Second Ed. New Jersey: Lawrence Erlbaum Associates, Inc., 2005, 377-410.

16. Horton RS, Bleau G, Drwecki B. Parenting narcissus: what are the links between parenting and narcissism? J Pers 2006; 74:345-376.

17. Kernberg O. Borderline conditions and pathological narcissism. USA: Rowman and Littlefield Publishers, Inc., 2004, 227-347.

18. Young JE, Klosko JS, Weishaar ME. Schema theraphy: a practitioner's guide. New York: The Guilford Press, Inc., 2003.

19. Cramer P. Adolescent parenting, identification, and maladaptive narcissism. Psychoanal Psychol 2015; 32:559-579. [CrossRef] 
20. Vaillant GE. Theoretical hierarchy of adaptive ego mechanisms: a 30-year follow-up of 30 men selected for psychological health. Arch Gen Psychiatry 1971; 24:107-118. [CrossRef]

21. Bowins B. Personality disorders: a dimensional defense mechanism approach. Am J Psychother 2010; 64:153-169. [CrossRef]

22. Cramer P. The Development of defense mechanisms: theory, research, and assessment. First Ed. New York: Springer-Verlag, 1991, 15-35. [CrossRef]

23. Masterson JF. The personality disorders: a new look at the developmental self and object relations approach. Phoenix: Zeig, Tucker and Co. Inc., 2000, 5-75.

24. Kohut $\mathrm{H}$. The analysis of the self: a systematic approach to the psychoanalytic treatment of narcissistic personality disorders. Chicago: The University of Chicago Press, 1971, 37-86.

25. Mahler MS, Pine F, Bergman A. The psychological birth of the human infant: symbiosis and individuation. New York: Basic Books, 1975.

26. Kernberg O. Borderline personality organization. J Am Psychoanal Assoc 1967; 15:641-685. [CrossRef]

27. Akhtar S, Byrne JP. The concept of splitting and its clinical relevance. Am J Psychiatry 1983; 140:1013-1016. [CrossRef]

28. Weinstock AR. Family environment and the development of defense and coping mechanisms. J Pers Soc Psychol 1967; 5:6775. [CrossRef]

29. Lopez FG. Adult attachment orientations, self-other boundary regulation, and splitting tendencies in a college sample. J Couns Psychol 2001; 48:440-446. [CrossRef]

30. Giovazolias T, Karagiannopoulou E, Mitsopoulou E. Can the factor structure of Defense Style Questionnaire (DSQ40) contribute to our understanding of parental acceptance/ rejection, bullying, victimization and perceived well-being in greek early adolescents? Eur J Psychol 2017; 13:269-285. [CrossRef]

31. Pincus AL, Ansell EB, Pimentel CA, Cain NM, Wright AGC, Levy KN. Initial construction and validation of the pathological narcissism inventory. Psychol Assess 2009; 21:365-379. [CrossRef]

32. Buyukgungor A. Adaptation of pathological narcissism scale into turkish. Master's Thesis, Bahçeşehir University Institute of Social Sciences, Istanbul, 2016.

33. Raskin R, Hall CS. The Narcissistic Personality Inventory: alternative form reliability and further evidence of construct validity. J Pers Assess 1981; 45:159-162. [CrossRef]

34. Ames DR, Rose P, Anderson CP. The NPI-16 as a short measure of narcissism. J Res Pers 2006; 40:440-450. [CrossRef]

35. Atay S. Standardization of Narcissistic personality inventory to Turkish. Journal of Gazi University Faculty of Economics and Administrative Sciences 2009; 11:181-196.

36. Gungor ND, Selcuk FU. Narcissistic Personality Inventory (NPI16): Turkish Adaptation. Unpublished Discussion Text, Atılım University Social Sciences Research and Education Laboratory (SAEL), 2015.

37. Andrews G, Singh M, Bond M. The Defense Style Questionnaire. J Nerv Ment Dis 1993; 181:246-256. [CrossRef]
38. Yilmaz N, Gencoz T, Ak M. Psychometric features of the defense style questionnaire: reliability and validity study. Turk Psikiyatri Derg 2007; 18: 244-253.

39. Arrindell WA, Sanavio E, Aguilar G, Sica C, Hatzichristou C, Eisemann M, et al. The development of a short form of the EMBU: Its appraisal with students in Greece, Guatemala, Hungary and Italy. Pers Individ Dif 1999; 27:613-628. [CrossRef]

40. Dirik G, Yorulmaz O, Karanci AN. Evaluation of parental attitudes in childhood: Brief perceived parental attitudes scalechild form. Turk Psikiyatri Derg 2015; 26:123-130.

41. Gerson MJ. Splitting: The development of a measure. J Clin Psychol 1984, 40:157-162. [CrossRef]

42. Alkan GS. Projective identification in peer-to-peer relationships: The binding role of projective identification between early maladaptive parenting experiences, personality structures and partner relationships. Doctoral Dissertation, The Middle East Technical University Institute of Social Sciences, Ankara, 2010.

43. Akinci I. The relationship between types of narcissism and psychological well-being: The role of emotions and emotion regulation difficulties. Master Thesis, Middle East Technical University Institute of Social Sciences, Ankara, 2015.

44. Lee SY, Gregg AP, Park SH. The person in the purchase: narcissistic consumers prefer products that positively distinguish them. J Pers Soc Psychol 2013; 105:335-352. [CrossRef]

45. Kaya L, Kalkan M. Narcissistic tendencies, attachment styles and social media use among university students. Journal of Higher Education and Science 2019; 9:243-249. [CrossRef]

46. Uzumcu E. Examination of factors associated with grandiose and vulnerable narcissistic personality traits within the framework of the schema therapy model. Master's Thesis, Hacettepe University Institute of Social Sciences, Ankara, 2016.

47. Foster JD, Campbell WK, Twenge JM. Individual differences in narcissism: Inflated self-views across the lifespan and around the world. J Res Pers 2003, 37:469-486. [CrossRef]

48. Miller JD, Campbell WK. Comparing clinical and socialpersonality conceptualizations of narcissism. J Pers 2008; 76:449476. [CrossRef]

49. Wardetzki B. Female Narcissism: Living at the Margins- Hunger for Acceptence. Ozturk FS, Ogunmez M (Translation Editor) Istanbul: Sistem Yayincilik, 2010.

50. Morf CC, Rhodewalt F. Unraveling the paradoxes of narcissism: A dynamic self-regulatory processing model. Psychol Inq 2001; 12:177-196. [CrossRef]

51. Holtzman NS, Strube MJ. The intertwined evolution of narcissism and short- term mating: An emerging hypothesis: In Campbell W K, Miller JD (editors). The handbook of narcissism and narcissistic personality disorder: theoretical approaches, empirical findings, and treatments. Hoboken: John Wiley and Sons Inc., 2011, 210-220. [CrossRef]

52. Cai H, Kwan VS, Sedikides C. A sociocultural approach to narcissism: The case of modern China. Eur J Pers 2012; 26:529535. [CrossRef] 
53. Kapidzic S. Narcissism as a predictor of motivations behind Facebook profile picture selection. Cyberpsychol Behav Soc Netw 2013; 16:14-19. [CrossRef]

54. Twenge JM, Foster JD. Birth cohort increases in narcissistic personality traits among American college students, 1982-2009. Soc Psychol Personal Sci 2010; 1:99-106. [CrossRef]

55. Twenge JM, Konrath S, Foster JD, Campbell WK, Bushman BJ. Egos inflating over time: a cross-temporal meta-analysis of the narcissistic personality inventory. J Pers 2008; 76:875-902.

56. Twenge J M (2011). Narcissism and culture: In Campbell K, Miller JD (Editors). The handbook of narcissism and narcissistic personality disorder: theoretical approaches, empirical findings, and treatments. Hoboken: John Wiley and Sons, Inc., 2011, 202-209.

57. DeWall CN, Pond RS, Campbell WK, Twenge JM. Tuning in to psychological change: linguistic markers of psychological traits and emotions over time in popular US song lyrics. Psychol Aesthet Creat Arts 2011, 5:200-207. [CrossRef]

58. Otway LJ, Vignoles VL. Narcissism and childhood recollections: a quantitative test of psychoanalytic predictions. Pers Soc Psychol Bull 2006; 32:104-116. [CrossRef]

59. Huxley E, Bizumic B. Parental invalidation and the development of narcissism. J Psychol 2017; 151:130-147. [CrossRef]

60. Clemence AJ, Perry JC, Plagkun EM. Narcissistic and borderline personality disorders in a sample of treatment refractory patients. Psychiatr Ann 2009; 29:175-184. [CrossRef]

61. Cramer P. Personality, personality disorders, and defense mechanisms. J Pers 1999; 67:535-554. [CrossRef]

62. Johnson JG, Bornstein RF, Krukonis AB. Defense styles as predictors of personality disorder symptomatology. J Pers Disord 1992; 6:408-416. [CrossRef]

63. Perry JD, Perry JC. Conflicts, defenses and the stability of narcissistic personality features. Psychiatry 2004; 67:310-330.
64. Richardson EN, Boag S. Offensive defenses: the mind beneath the mask of the dark triad traits. Pers Individ Dif 2016; 92:148152. [CrossRef]

65. Gould JR, Prentice NM, Ainslie RC. The splitting index: construction of a scale measuring the defense mechanism of splitting. J Pers Assess 1996; 66:414-430. [CrossRef]

66. Watson PJ, Biderman MD. Narcissistic personality inventory factors, splitting, and self-consciousness. J Pers Assess 1993; 61:41-57. [CrossRef]

67. Vaillant GE. Adaptation to life. Boston: Little Brown, 1977.

68. Hart W, Adams J, Burton KA, Tortoriello GK. Narcissism and self-presentation: Profiling grandiose and vulnerable Narcissists' self-presentation tactic use. Pers Individ Dif 2017; 104:48-57. [CrossRef]

69. Perry JC, Presniak MD, Olson TR. Defense mechanisms in schizotypal, borderline, antisocial, and narcissistic personality disorders. Psychiatry 2013; 76:32-52. [CrossRef]

70. Afek O. The split narcissist: the grandiose self versus the inferior self. Psychoanal Psychol 2018; 35:231-236. [CrossRef]

71. Miller JD, Hoffman BJ, Gaughan ET, Gentile B, Maples J, Keith Campbell W. Grandiose and vulnerable narcissism: a nomological network analysis. J Pers 2011;79:1013-1042.

72. Ellison WD, Levy KN, Cain NM, Ansell EB, Pincus AL. The impact of pathological narcissism on psychotherapy utilization, initial symptom severity, and early-treatment symptom change: a naturalistic investigation. J Pers Assess 2013; 95:291-300. [CrossRef]

73. Masterson JF. The emerging self: a developmental, self, and object relations approach to the treatment of the closet narcissistic disorder of the self. Philadelphia: Brunner/Mazel Inc., 1993.

74. Masterson JF. The narcissistic and borderline disorders: an integrated developmental approach. New York: BrunnerRoutledge Inc., 1981. 